\title{
Psychogenic vomiting: the relation between patterns of vomiting and psychiatric diagnoses
}

\author{
M Muraoka, K Mine, K Matsumoto, Y Nakai, T Nakagawa
}

\begin{abstract}
Fifty nine patients admitted with a diagnosis of psychogenic vomiting were classified into five patterns of vomiting: continuous, habitual postprandial, irregular vomiting, nausea, and self induced. The psychiatric disorders related to the onset of vomiting were either a major depression or a conversion disorder. Continuous vomiting was usually due to a conversion disorder, while in many cases of habitual postprandial and irregular vomiting, major depression was observed. The patients' psychiatric disorders and vomiting patterns often changed during the clinical course. Assessing the psychiatric problems and vomiting patterns is important in the diagnosis and treatment of psychogenic vomiting.
\end{abstract}

Psychogenic vomiting is defined by Leibovich ${ }^{1}$ as vomiting without any obvious organic pathology, or 'functional' vomiting, resulting from psychological mechanisms. Several authors have reported the psychological background of psychogenic vomiting, and a relationship with hysterical neurosis or depression has been suga parent in their childhood and felt trapped in a hostile relationship. The aetiology and pathophysiology of psychogenic vomiting is unclear and guidelines as to its treatment have not yet been established.

We studied patients admitted to our department during the past 15 years for psychogenic vomiting, paying particular attention to patterns of vomiting and the psychiatric assessment in relation to its onset. We have attempted to classify psychogenic vomiting according to its clinical usefulness and would like to present typical cases of each category and to describe their treatment.

\section{Methods}

Department of Psychosomatic Medicine, Kyushu University, Fukuoka 812, Japan

MMuraoka

K Mine

K Matsumoto

Y Nakai

T Nakagawa

Correspondence to: Kazunori Mine MD, Department of Psychosomatic Medicine, Faculty of Medicine, Kyushu University, Maidashi 3-1-1, Higashi-ku, Fukuoka 812, Japan.

Accepted for publication 10 July 1989

In the 15 years from 1974 to 1988,59 patients were admitted to the Department of Psychosomatic Medicine of Kyushu University Hospital who were diagnosed as having psychogenic vomiting. No organic lesions were found in any patients after thorough physical, laboratory, radiological, ultrasonic scanning and endoscopic examinations. ${ }^{46}$ There were 41 women and 19 men. Their ages ranged from 10 to 63 years, with a mean of $27 \cdot 8$ years (SE $1 \cdot 4)$. The mean duration of the vomiting from its onset was 45.4 months (SE 10.5). In particular, the patterns of vomiting of these patients were studied. gested..$^{12} \mathrm{Hill}^{3}$ found that many patients had lost

A psychological evaluation and psychiatric diagnosis was established for each patient using psychological tests and psychiatric assessment. The psychiatric diagnoses were based on the Diagnostic Criteria from DSM-III-R (American Psychiatric Association, 1987). A basic battery of psychological tests consisted of Cornell Medical Index (CMI), ${ }^{7}$ Selfrating Depression Scale by Zung (SDS, ${ }^{8}$ Yatabe-Guilford test (YG test) ${ }^{9}$ and Picture-Frustration study by Rosenzweig (PF study). ${ }^{10}$ Patients were also rated on Minnesota Multiphasic Personality Inventory (MMPI)." We also noted whether a correlation between the patterns of vomiting and the psychiatric diagnosis existed.

\section{Results}

CLASSIFICATION OF VOMITING PATTERNS Five patterns of vomiting could be distinguished before admission: continuous vomiting, habitual postprandial vomiting, irregular vomiting, nausea and self-induced.

Patients with continuous vomiting showed episodes of severe vomiting at intervals usually ranging from several minutes to half an hour, and continuing for more than one day. These episodes tended to recur weekly or monthly. The vomitus consisted of food remnants initially, often changing almost entirely to saliva, gastric juice and bile, while the amount gradually diminished to a very small quantity. This type of vomiting occurred in 22 of 59 patients.

Postprandial vomiting was usually accompanied by anorexia and weight loss. The mean weight loss was $12.5 \%$ of the standard weight according to age and height (SE 6.1\%). There were 11 patients in this category.

In patients with irregular vomiting, the vomiting was not necessarily related to the meals, and weight loss was rare. There were 14 patients with this type of vomiting.

Nausea alone was seen in nine patients.

Three patients with selfinduced vomiting did so in order to relieve a feeling of discomfort in the upper abdomen.
DISTRIBUTION OF PSYCHIATRIC DIAGNOSES

Psychological tests were conducted by psychiatric assessment through interviews and estimation of the effects of psychotropic drugs and a diagnosis of psychotropic disorder was considered to be strongly related to the onset of vomiting.

There were 31 patients whose vomiting appeared to be the symptom of a conversion 
disorder. All fulfilled the criteria of a conversion disorder according to DSM-III-R.

A major depression, fulfilling the criteria of the DSM-III-R, was considered to be strongly involved in the onset of vomiting in 21 cases, including six cases all showing weight loss of more than $25 \%$ of the standard weight according to age and height. It was not, however, accompanied by a fear of becoming obese or disturbance of their body image.

In many instances, more than one psychiatric disorder was recognised as related to the patients' vomiting, but the one with the strongest relation was taken as 'the psychiatric disorder involved in the onset of vomiting'.

There were six patients with a generalised anxiety disorder and one patient with an obsessive compulsive disorder. These were grouped together as 'other psychiatric diagnoses'.

\section{SOMATIC BACKGROUND}

To assess the somatic background, the medical histories of the patients were examined. There were 17 cases with a history of severe habitual car sickness; eight patients with irritable bowel syndrome, four with gastric and duodenal ulcers and 10 patients with other diseases, such as acute viral hepatitis, hyperemesis gravidarum and adhesion ileus.

\section{RELATION BETWEEN PSYCHIATRIC} DIAGNOSIS AND VOMITING PATTERNS

We investigated the correlation, if any, between the patterns of vomiting and the psychiatric disorders considered to be related to the onset of vomiting (Table I). The vomiting patterns and the psychiatric diagnoses appeared not to be entirely unrelated $\left(\chi^{2}\right.$-test for a $3 \times 5$-table: $\mathrm{p}<0.001$ ).

In patients with continuous vomiting, conversion disorder was common, being $91 \%$. Conversely, $65 \%$ of the patients diagnosed as having a conversion disorder showed continuous vomiting. The correlation between the presence of continuous vomiting and the diagnosis of a

TABLE I Relation between vomiting patterns and psychiatric diagnoses in psychogenic vomiting

\begin{tabular}{lllllll}
\hline \multirow{2}{*}{$\begin{array}{l}\text { Psychiatric } \\
\text { diagnoses }\end{array}$} & Vomiting patterns & & & & \\
\cline { 2 - 7 } & Continuous & Postprandial & Irregular & Nausea & Self-induced & Total \\
\hline Conversion disorder & 20 & 4 & 4 & 2 & 1 & 31 \\
Major depression & 2 & 7 & 10 & 1 & 1 & 21 \\
Other diagnoses & 0 & 0 & 0 & 6 & 1 & 7 \\
\hline Total & 22 & 11 & 14 & 9 & 3 & 59 \\
\hline
\end{tabular}

TABLE II Some typical cases of psychogenic vomiting

\begin{tabular}{|c|c|c|c|c|}
\hline & \multicolumn{4}{|c|}{ Patients (sex and age) } \\
\hline & $\begin{array}{l}\text { Patient } 1 \\
\text { (m 51) }\end{array}$ & $\begin{array}{l}\text { Patient } 2 \\
(f 24)\end{array}$ & $\begin{array}{l}\text { Patient } 3 \\
\left(\begin{array}{l}m \\
22\end{array}\right)\end{array}$ & $\begin{array}{l}\text { Patient } 4 \\
(f 27)\end{array}$ \\
\hline $\begin{array}{l}\text { Psychiatric } \\
\text { diagnosis } \\
\text { Vomiting type } \\
\text { Somatic factors }\end{array}$ & $\begin{array}{l}\text { Conversion } \\
\text { disorder } \\
\text { Continuous } \\
\text { Acute viral } \\
\text { hepatitis }\end{array}$ & $\begin{array}{l}\text { Major depression } \\
\text { Postprandial } \\
\text { Severe } \\
\text { carsickness }\end{array}$ & $\begin{array}{l}\text { Obsessive com- } \\
\text { pulsive disorder } \\
\text { Self-induced } \\
\text { Osteogenesis } \\
\text { imperfecta }\end{array}$ & $\begin{array}{l}\text { Generalized } \\
\text { anxiety disorder } \\
\text { Nausea } \\
\text { Multiple } \\
\text { laparotomies }\end{array}$ \\
\hline
\end{tabular}

conversion disorder was statistically significant $\left(<0.001, \chi^{2}\right.$-test for a $2 \times 2$-table) .

In patients with habitual postprandial vomiting, major depression was observed in $64 \%$ and a conversion disorder in $36 \%$. The correlation between the presence of habitually postprandial vomiting and the diagnosis of a major depression was statistically significant $\left(\mathrm{p}<0.05, \chi^{2}\right.$-test for $2 \times 2$-table).

In patients with irregular vomiting, a major depression was frequently seen $-71 \%$ of cases; this correlation was statistically significant $\left(\mathrm{p}<0.001, \chi^{2}\right.$-test for a $2 \times 2$-table). There was also a considerable number of irregular vomiting patients who were diagnosed as having a conversion disorder (29\%).

In $67 \%$ of patients with nausea, other psychiatric disorders such as a generalised anxiety disorder, were involved at the onset.

A summary of typical patients is shown in Table II. All cases were treated by physicians trained in internal medicine and psychosomatic medicine.

\section{Discussion}

In our patients vomiting almost never appeared purely as a manifestation of emotional conflicts, but in most cases there was a combination of past organic or gastrointestinal functional abnormalities and emotional problems. Almost all patients had vomiting in their medical history such as car sickness or vomiting during acute viral hepatitis, or hyperemesis gravidarum. According to Rosenthal $e t$ al and Hill, vomiting once experienced during organic or functional disease, becomes reinforced by short term benefits at these events and in fact becomes a habit, and can be regarded as a learned form of behaviour. ${ }^{312}$

There have been several reports concerning the psychiatric factors involved in the onset of psychogenic vomiting. Leibovich has already pointed out the relationship was 'hysterical neurosis, depression and personality disturbances'.' Swanson et al reported 77 patients who had nausea as their main complaint, although in $73 \%$ of patients it was accompanied by vomiting; ${ }^{2}$ in other words, they could be regarded as belonging to the nausea type of psychogenic vomiting. Among these 77 patients, there were 16 patients diagnosed as having 'hysterical neurosis' and 21 patients with 'depressive neurosis'. Rosenthal et al reported 18 patients among whom only three were diagnosed as having a major depression, while 12 had various adjustment problems. ${ }^{12}$ In our study, conversion disorders and major depressions were the psychiatric factors most frequently seen with the onset of psychogenic vomiting. A conversion disorder was often seen in patients recovering from depression. In this way, the patients' psychiatric disorders often changed during the clinical course of the psychogenic vomiting.

In this study, statistically significant correlations between certain vomiting patterns and psychiatric diagnoses were suggested. Patients showing continuous vomiting were mainly diagnosed as having a conversion disorder, while among patients with habitual postprandial or irregular vomiting, a major 
depression was most often seen. Changes in the vomiting pattern from the continuous type to the postprandial or irregular types were often observed. Conversely, patients with continuous vomiting sometimes had initially belonged to the postprandial or irregular vomiting type or to the nausea type.

Hill reported that in all his 20 cases of psychogenic vomiting, the vomiting was worse at meal times, starting on during the meal or soon after, accompanied by nausea in all but one patient. ${ }^{3}$ From this study, it can be concluded that there are more patterns of psychogenic vomiting than have previously been described.

Concerning treatment, Rosenthal et al concluded that most psychogenic vomiting patients could be treated effectively by an empathetic primary care physician. ${ }^{12}$ Weddington and Stravynski suggested behavioural therapy as treatment. ${ }^{13 ! 4}$ Haggerty et al and Golden et al reported good results using antidepressants. ${ }^{15} 16$ In our patients, we used a combination of pharmacotherapy (minor and major tranquilizers, and anti-depressants) as well as supportive psychotherapy, behavioural therapy and autogenic training.

The following factors should be taken into account for treatment of psychogenic vomiting: there is a correlation between certain vomiting patterns and psychiatric disorders. In patients with continuous vomiting, which is often so severe that organic disease is suspected, the vomiting is almost always the result of a conversion disorder. In many cases of habitual postprandial vomiting and irregular vomiting, the onset of the vomiting is related to major depression. The psychological background should be carefully considered in the choice of treatment. This psychiatric disorder can change during the clinical course, so that treatment should be adapted in such instances.

1 Leibovich MA. Psychogenic vomiting: psychotherapeutic considerations. Psychother Psychosom 1973; 22: 263-8.

2 Swanson DW, Swenson WM, Huizenga KA, Melson SJ. Persistent nausea without organic cause. Mayo Clin Proc 1976; 51: 257-62.

3 Hill OW. Psychogenic vomiting. Gut 1968; 9: 348-52.

4 Malagelada J. Unexplained vomiting: a diagnostic challenge. Ann Intern Med 1984; 101: 211-8.

5 Hanson JS. The diagnosis and management of nausea and vomiting: a review. Gastroenterology 1985; 80: 210-8.

6 Salmon PR. Eosinophilic granuloma of the gastro-intestinal Tract. Gut 1967; 8: 8-14.

7 Brodman K et al. Cornell Medical Index-Health Questionnaire Manual (Revised 1955) from the New York Hospital and the Department of Medicine (Neurology) and Psychiatry, Cornell University Medical College.

8 Zung WWK, Durham NC. A self-rating depression scale. Arch Gen Psychiat 1965; 12: 63-70.

9 Guildford JP, Zimmerman WS. The Guildford-Zimmerman temperament survey: manual of instruction and interpretations. Beverly Hills, California: Sheridan Supply Co, 1949.

10 Rosenzweig S. The Rosenzweig picture-frustration study basic manual. Rana House, 1978.

11 Dahlstrom WG, Dahlstrom $\mathrm{L}$, eds. Basic readings on the $M M P I$ - a new selection on personality measurement. Minneapolis: Univ of Minn Press, 1980.

12 neapolis: Univ of Minn Press, Wriable LD. Diagnosis and Management of persistent psychogenic vomiting. PsychoManagement of persisten
somatics 1980; $21: 722-30$

13 Weddington WW. Psychogenic nausea and vomiting associated with termination of cancer chemotherapy. Psychother Psychosom 1982; 37: 129-36.

14 Stravynski A. Behavioral treatment of psychogenic vomiting in the context of social phobia. $\mathcal{F}$ Nerv Ment Dis 1983; 171: 448-51.

15 Haggerty JJ, Golden RN. Psychogenic vomiting associated with depression. Psychosomatics 1982; 23: 91-5.

16 Golden RN, Janke I, Haggerty JJ. Amoxapine treatment of psychogenic vomiting and depression. Psychosomatics 1988 ; 29: $352-4$. 